\title{
New Exploration by Means of Intuition in the Field of Children's Art Education
}

\author{
Yanqing Hou \\ Feixian School, Linyi University, Feixian, Shandong, 273400, P.R. China \\ lydxmfl@126.com
}

\begin{abstract}
Intuition plays an important role in children's art education, for intuition enables children to grasp the basic characteristics of the object and represent visual image in a creative way so as to demonstrate the natural rule of beauty. This paper is divided into three parts. The first part points out the problems in children's art education. The second part analyzes the role of intuition in children's art education. The third part discusses the ways of intuition training with a view to providing some new solutions to the problems that occur in the process of children's art education.

Index Terms - Intuition, Children's art education, Traditional art education, Visual training, Visual expression.
\end{abstract}

\section{Introduction}

Comparing with other countries, China is a late starter in the study of intuition in art eduction. Thus, just a few materials on the ways of using intuition are available to us. Explorations of the Reliance of Children's Art Education on Intuition, a paper by Professor Yang Jingzhi from Beijing Normal University, proposes that relying on intuition, children can grasp the basic characteristics of the object and represent visual images in a creative way so as to demonstrate the natural rule of beauty. This paper provides the theoretical foundation for the author. On the Relationship between Intuition and Children's Art Education by Huang Yanmin gives credit to the role of intuition in children's art education, serving as a valuable reference to the author. Unfortunately, both papers fail to touch on the ways of using intuition. To fill the gap, this paper makes a tentative study on the ways of training children's intuition with a view to providing some new solutions to the problems that occur in the process of children's art education.

\section{Problems in China's Traditional Children's Art Education}

\subsection{Traditional children's art education views children's growth from the perspective of adults}

The traditional art teaching materials are not in accordance with children's reality. Viewing children's growth from the perspective of adults appears to agree with the principles of gradual progress from the elementary to profound. However, such a view ignores the fact that children don't know the world from he easy to the difficult. They prefer to draw the persons and things they are familiar with and interested in. Practive shows that children's painting subjects know no complexity. Instead, the changeful and complicated shapes are more popular among children. Kindergarten, sneakers and bicycles in primary school textbooks, for example, are all good subjects of painting for the children.[1,2] .

\subsection{Traditional children's art education puts too much emphasis on rational knowledge and skills}

Traditional art teaching focuses on copying, overlooking children's individual representation. The simplified graphics are often used as models of representing images, which are instilled in children by means of copying. By teaching children to paint stick figures, the teachers claim that children have grasped painting skills. Children are mimics by nature. Thus, if they are taught to paint the stereotypical things at the very beginnings, then the mind-set will gradually be formed, for the first impressions are the strongest. Once children learn the patterned formula, all their paintings will be in the same pattern, be it sun, bird, flower or tree. Teaching art by means of copying deprives the children of the ability to feel the beauty. So much so that they lose the courage and ability to draw those vivid and interesting images. Their paintings are just stereotypes with no individuality and unable to evoke emotional feelings.

\subsection{Evaluation criteria in traditional art education hinders children's creativity}

In traditional art education, children's paintings are evaluated by whether they are like the original or not. The more the paintings are like the teacher's model ones, the better they are. However, Such criteria ignores the diversified representation of art.[3,4]. Different people with different feelings towards life will have different ways of expression. Thus, the requirements of uniformity in the art education will and consequently lead to lifelessness, stiffness and sameness of children's paintings.

Different children, influenced by different environments, dispositions and ways of upbringing, will have different aesthetic values and abilities. Difference of aesthetic feelings is common and absolute. In this sense, only by stressing individuality and advocating innovation in art education can the children develop their creativity.

The accuracy of shape is also an important aspect in traditional art education. Painting with accurate proportion at he very beginning is actually beyond children's abilities. Instead of asking students to represent the vivid and colorful typical images by means of observation so as to express their understandings of life, the traditional art education puts more emphasis on skills. Such a way, therefore, inhibits children's initiative to some degree. 


\section{The Role of Intuition in the Children's Art Education}

Intuitive perception and rational analysis are human being's two basic cognitive processes, playing their roles in a cooperative manner. Intuition is an emotional activity and cognitive ability at once, on which children rely to develop their cognition. Emotional wisdom plays an especially leading role in artistic activities. Children's paintings are characteristic of making plane, imaginal, expressive and decorative perceptual creations, providing foundation for the system of children's painting courses. The characteristics of children's paintings relying on intuitions can be summed up as follows:

\subsection{Intuition enables children to grasp the basic characteristics of the object}

Children firstly use intuitive visual thinking in observation. They will make selections of and put emphasis on things that attract their attentions so as to demonstrate the characteristics of the object.[1]. From the aesthetic point of view, how the object is perceived constitutes the essence of the object. For example, a four-year-old child will draw an oval to represent the body of the bird, a triangle or just a line at one end of the oval to represent the beak of the bird, and two lines or two triangles at two sides of the oval to represent the wings of the bird. This example shows that children are more likely to paint in an abstract and general way. As they grow up, their memory and power of observation will strengthen, hence they will represent images in a more complicated and realistic way. It's a natural process of children's cognitive development to represent images from the easy way to the complicated way.

It's an important approach for human being $\mathrm{s}$ to understand life through sense organs, which, therefore, constitutes an important aspect in the process of children's cognitive development. To meet the requirements of the artistic expression, one should paint the concrete images with characteristics that can distinguish the images from others instead of painting the concept of the images. Therefore, teachers are advised to keep enlightening and guiding the children to observe the characteristics of the images and then distinguish one from another so as to achieve the goal of developing their cognition through intuitions, enhancing their abilities of artistic expression and liberating them from the conceptual representation in painting.

\subsection{Intuition enables children to represent visual images in a creative way}

Children's early artistic forms consist of highly abstract geometries, which reflect, rather than replicate the essential characteristics of the nature. Actually, contrary to that of adult, the children's artistic generalization is irrational mental activity.[3]. Generalization occurs spontaneously in all senses, for only the simplified images will be remembered. Children pay more attention to the subjective needs when representing visual images and they are unusually creative in representing the fundamental structural characteristics of the world. For example, to draw the cars running on the road, a four-year-old child will firstly draw a line, and then two skies up and down the line, and the cars and pedestrians will be represented on the line upside down. Another example, to draw a person washing hair, the children will represent the hair put in the basin and the ground on which the person stand from the downward angle so as to provide a clear view of hair washing, and represent the person's body from the horizontal angle so as to paint how the person stand in a dynamic way.

\subsection{Intuition enables children to feel the natural law of the beauty and try to represent it}

Experience and pursuit of the order, balance and harmony in the nature are naturally demonstrated in children's paintings.[5]. For example, when drawing from nature, children can always present the complicated scenes in an organized manner; in children's color paintings, complementary colors are often used to manifest the strong but harmonious relationship between colors. Children can sense the face is green in front of red backdrop, and they can also represent the changes in brightness resulted from the influence of the light on the images with color blocks differing in brightness and purity. All the above are natural expressions by virtue of intuitive and subjective feelings rather than artistic expressions based on rational knowledge. In this sense, teachers should give more credits to the strong points of children's paintings and consciously direct children from unconscious natural development to conscious artistic expression.

\section{Ways of Training Intuition}

\subsection{Teaching principles of intuition training}

Teachers are the guiders while children are the subjects. Teachers are supposed to create opportunities for the children to freely express, explore and create with a view to promoting their physical and mental health and harmonious development.

Determine teaching contents and requirements at different stages according to children's psychological characteristics and abilities at different ages so as to ensure the continuity in teaching.

Develop children's senses and aesthetic awareness by virtue of intuitive perception. Various means should be used to broaden children's horizon, stimulate their interest in creation, and train children's creativity in visual modeling and their ability of emotional expression.

Teachers should try not to demonstrate techniques, but do heuristic teaching by means of observing, memorizing, experiencing, associating and appreciating. In this way, the children will learn the ways of using various drawing tools and materials and applying modeling elements and rules instead of being limited to just one expression way.

\subsection{Ways of training intuition modeling}

4.2.1 Develop children's ability of observation, memory, imagination and creation with focus on visual training

Firstly, the children are required to observe. Children are used to painting the images they remember but not spend time carefully observing the objects, which, in children's opinion, 
are irrelevant to their paintings. In this case, directing children's attention to observation can help children get rid of conceptualization in modeling.

Secondly, teachers should teach children useful ways to observe and memorize the shape, such as the shape features of the object, difference from other objects, the specific contents and details of the object, relationship between different objects, spatial distance between objects and the changes of the color.

Thirdly, the teaching materials should be serialized. Various media, such as real objects, videos, pictures and slides should be utilized to form interconnected teaching contents so as to stimulate children's senses and evoke their interest in creation.

\subsubsection{Liberate children from reproduction and replication and respect children's visual expression}

Children don't intend to draw a picture exactly similar to the original. Thus, children's paintings have nothing to do with skills. Faithfully copying the original is by no means the only yardstick to evaluate the artistic works, which, on the contrary, hinders children's free and creative expression.[6]. Only by teaching the children necessary knowledge in an acceptable way to develop their ability of feeling the beauty, can they express their aesthetic consciousness by means of painting.

Therefore, to foster the children's aesthetic awareness, appropriate knowledge points should be selected. The socalled "mistakes" for which the children are often be criticized should be regarded as children's legitimate painting style and inevitable features. Thus, in children's art education, teachers should let nature take its course and tailor their teaching methods according to children's different abilities.Thus, if teachers can give full play to children's leaning enthusiasm and initiative, they, with great potential, will paint like masters intuitively.

\section{Summary}

There are both differences and connections between children's art education and professional art education. Children's art education puts much emphasis on intuitive perception and encourages the children to engage all their senses in to find, feel, express and create beauty by means of such activities as observing, memorizing, associating and creating.

\section{References}

[1] B.Y.Yuan, The problem and countermeasure of logistics management professional undergraduate course education in our country. Tianjin publishing press, Tianjin, china, 2008. (In Chinese)

[2] G.L. Zhou, Reform and exploration of the personnel training mode, China's higher education Beijing publishing press, Beijing 2009. (In Chinese)

[3] Y.sh.Wu, Research of applied logistics management personnel innovation training mode. Journal of logistics technology, Heilongjiang Harbin publishing press. 2009. (In Chinese)

[4] D. Zhu, The thinking of innovative of logistics management major and applied undergraduate talents cultivation. Journal of logistics technology, Heilongjiang publishing press. Harbin. 2009. (In Chinese)

[5] Zh.J.Fan, The analysis of logistics management in colleges and universities undergraduate talents training mode. Journal of technology and market, Sichuan, chengdu, 2009. (In Chinese) 